\title{
STUDI ADAPTASI DAN KINERJA PERTUMBUHAN CENDANA (SANTALUM ALBUM L) PADA UMUR 11 TAHUN DI WATUSIPAT KABUPATEN GUNUNG KIDUL
}

\author{
Yayan Hadiyan dan Yuliah \\ Balai Besar Penelitian Bioteknologi dan Pemuliaan Tanaman Hutan
}

\begin{abstract}
Abstrak
Cendana (Santalum album) merupakan tanaman bernilai ekonomi tinggi yang kian terancam dan langka di daerah sebaran aslinya. Upaya penyelamatan jenis tersebut melalui konservasi eks situ telah dilakukan oleh berbagai pihak. Salah satu kegiatan konservasi tersebut dilakukan BBPBPTH tahun 2005 dengan melakukan koleksi material genetic dari beberapa populasi alam di Provinsi NTT. Tujuan penelitian ini adalah untuk melihat pertumbuhan tanaman Cendana dari 4 provenans alam pada umur 11 tahun di Kabupaten Gunung Kidul. Pengukuran dilakukan pada variable tinggi total pohon, tinggi bebas cabang dan diameter batang. Hasil analisis data menunjukan bahwa terdapat keragaman yang siginifikan antar provenance yang diuji untuk variable tinggi pohon dan diameter batang, sedangkan untuk tinggi bebas cabang tidak. Rerata pertumbuhan terbaik berasal dari proevans Rote (tinggi 6,07 m dan diameter batang 5,08 cm). Sedangkan untuk daya adaptasi terbaik adalah dari Rote (92,19\%).
\end{abstract}

Kata Kunci: Cendana, konservasi, persen hidup, pertumbuhan

\section{THE STUDY OF ADAPTATION AND GROWTH FOR SANDALWOOD (SANTALUM ALBUM L) ON 11 YEARS OLD AT WATUSIPAT GUNUNG KIDUL REGENCY}

\begin{abstract}
Sandalwood (Santalum album L) is a high-value economic tree species that is increasingly threatened and rare in the its natural distribution area. Efforts to save these species through ex-situ conservation have been done by various parties. One of the conservation activities was carried out by BBP-BPTH in 2005 by collecting genetic material from several natural populations at NTT Province. The purpose of this study is to see the growth performance of Cendana plants from 4 provenance of the age of 11 years in Gunung Kidul Regency. Measurements were performed on the total height variable of the tree, the height of the bole length and the stem diameter. The result of data analysis shows that there is significantly different from the population tested for the variable height of tree and the diameter of the stem, while for the bole length is not. The best performance of growth are from the Rote provenance (height is $6.07 \mathrm{~m}$ and diameter of stem is $5.08 \mathrm{~cm}$ ). As for
\end{abstract} the best adaptation ability is from Rote $(92.19 \%)$.

Key words : Adaptability, conservation, growth, sandalwood

(C) 2017 Yayan Hidayan, Yuliah Yuliah

\section{PENDAHULUAN}

Provinsi Nusa Tenggara Timur (NTT) adalah salah satu wilayah di Indonesia yang dikenal memiliki iklim yang kering. Musim kemarau berlangsung cukup panjang dari bulan Mei hingga Nopember, sedangkan musim hujan terjadi selama 5 bulan dari bulan Desember hingga April (Pemprov NTT, 2016). Akibat perubahan iklim, mayoritas kabupaten di NTT memiliki resiko berkurangnya curah hujan yang berkaitan dengan kejadian El Nino 
(Hasan dan Mongko, 2016). Hasil sensus BPS NTT (2013) menunjukkan luasan lahan potensial kritis hingga sangat kritis di dalam kawasan hutan seluas 1.691.930 ha. Di sisi lain menurut Hutabarat (2006) kemampuan Rehabilitasi Hutan dan Lahan (RHL) di NTT dalam 20 tahun terakhir hanya 3.615 ha.

Kondisi - kondisi tersebut telah mendorong jenis-jenis endemik berkurang, termasuk Cendana (Santalum album L) yang memiliki nilai ekonomi tinggi. Cendana merupakan salah satu jenis tumbuhan asli NTT yang memiliki nilai ekonomi tinggi. Tetapi ekploitasi tanaman cendana menyebabkan semakin berkurangnya populasi cendana di alam. Hasil inventarisasi pohon cendana selama kurun waktu 10 tahun (1987-1997) menunjukkan terjadinya penurunan hingga 53,96\% (Dinas Kehutanan Provinsi NTT, 1998, dalam Darmokusumo dkk, 2001). IUCN memasukan cendana ke dalam daftar jenis yang harus dilindungi dengan kategori Vulnerable A1d ver 2.3. Hal ini cendana berarti sedang menghadapi risiko kepunahan di alam liar pada waktu yang akan datang.

Terkait hal itu, untuk melestarikan cendana perlu dilakukan penelitian yang intensif. Kementrian lingkungan Hidup dan Kehutanan c.q Balai Besar Penelitian dan Pengembangan Bioteknologi dan Pemuliaan Tanaman Hutan, telah melakukan koleksmi materi genetic Cendana dan membangun konservasi Eks situnya di Gunung Kidul pada tahun 2005 dengan koleksi dari beberapa asal sumber benih. Selain untuk menlindungi dari cekaman iklim dan masalah lainnya Tujuan studi ini adalah untuk mengetahui daya adaptasi dan kinerja pertumbuhan Cendana umur 11 tahun tersebut di Gunung Kidul.

\section{BAHAN DAN METODA}

\section{A. Lokasi dan Waktu Penelitian}

Penelitian dilaksanakan pada Plot Konservasi Cendana tahun tanam 2005, di KHDTK Watusipat, Gunung Kidul. Lokasi penelitian berada pada ketinggian $150 \mathrm{~m}$ dpl, dengan curah hujan 1809 $\mathrm{mm} / \mathrm{th}$. Berdasarkan klasifikasi iklim Schmidt and Ferguson (1951), lokasi penelitian termasuk dalam tipe iklim C. Kondisi tanah berbatu dengan tingkat kesuburan yang rendah, tipe tanah grumusol hitam, bahan induk napal dan tufulkan intermediate. Topografi datar hingga bergelombang, dengan kemiringan $5-50 \%$ (BBPBPTH, 2013).

\section{B. Bahan dan Alat}

Bahan penelitian berupa tanaman pada plot konservasi eks situ Cendana yang berasal dari 5 Populasi, berumur 10 tahun. Kelima populasi tersebut berasal dari populasi: (1) Sumba, (2) Fatunisuan (Timor Tengah Utara), (3) Belu, (4) Soebela (Pulau Rote) dan (5) Imogiri. Alat yang digunakan berupa peta tanaman, tally sheet, alat tulis, galah ukur dan caliper.

\section{Design dan Pengukuran}

Desain penanaman cendana disusun dalam Rancangan Acak Lengkap Berblok (RCBD) dengan 5 populasi sebagai perlakuan, 4 blok sebagai ulangan dan 16 tree plot (individu) dalam setiap blok. Jarak tanam yang digunakan adalah $3 \times 3 \mathrm{~m}$. Pengamatan daya adaptasi tanaman dilakukan secara sensus dengan menghitung jumlah tanaman hidup. Kinerja pertumbuhan tanaman umur 11 tahun diamati dengan mengukur tinggi dan diameter batang. Tinggi tanaman diukur dengan menggunakan galah ukur dari permukaan tanah sampai dengan ujung tanaman, sedangkan diameter batang 
diukur dengan menggunakan kaliper pada titik setinggi dada $( \pm 130 \mathrm{~cm})$.

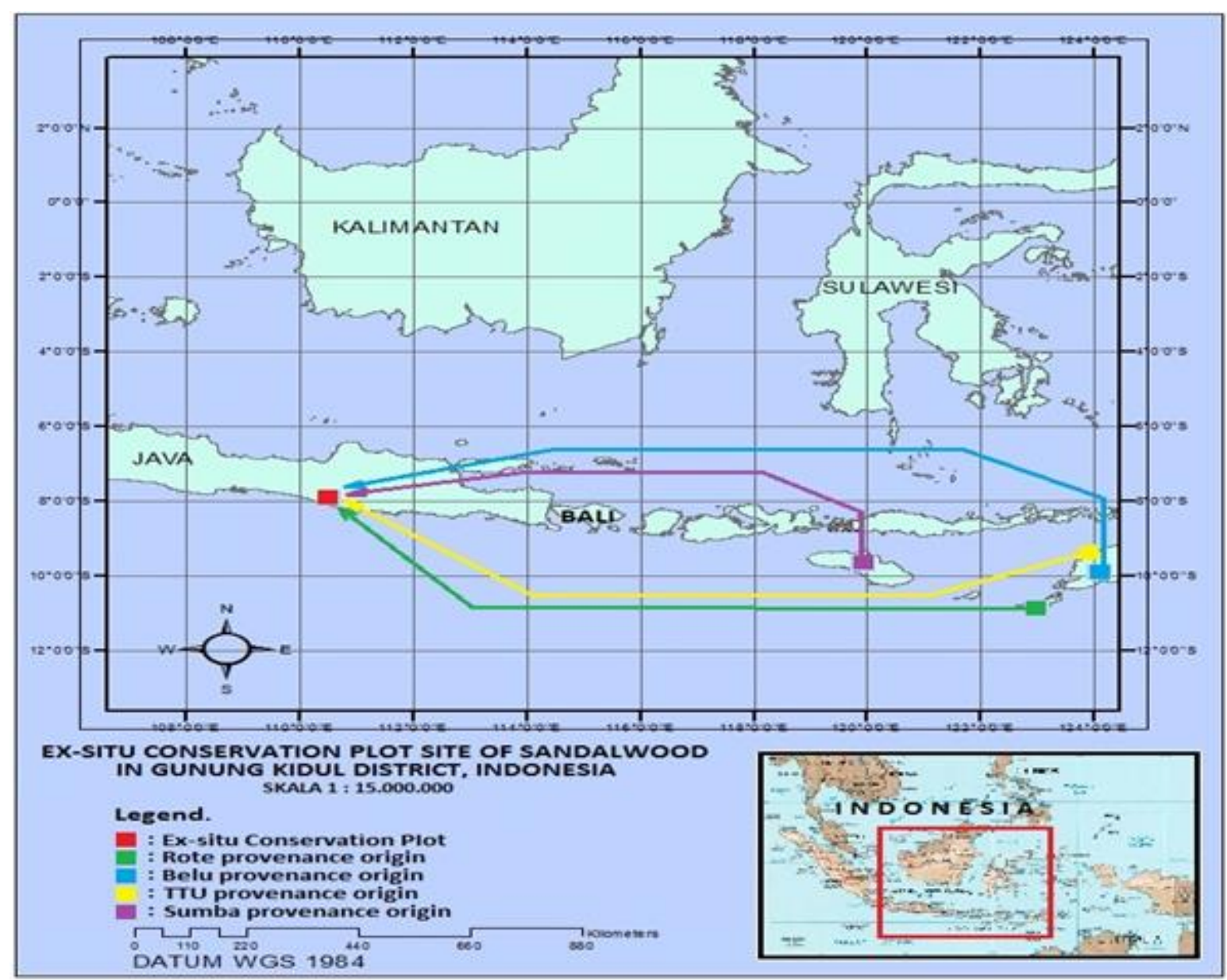

Gambar 1. Lokasi Plot Konservasi Eks Situ dan Populasi Asal Cendana yang diuji (Hadiyan dan Fiani, 2014)

\section{E. Analisis Data}

Daya adaptasi diketahui dengan menghitung persen hidup tanaman. Perhitungan persentase hidup dilakukan dengan menghitung jumlah tanaman hidup dibagi jumlah tanaman awal dikalikan 100\%.

Analisis pertembuhan Cendana dilakukan dengan analisis varian, menggunakan linier model sebagai berikut:

$Y \mathrm{ij}=\mu+\mathrm{Bi}+\mathrm{Pj}+\varepsilon \mathrm{ij}$

dimana:

Yij, $\mu, \mathrm{Bi}, \mathrm{Pi}$, and ij secara berurutan adalah rerata variabel yang diamati, rerata umum eksperimen, pengaruhblok ke-I, pengaruh populasi ke-j, dan error random
Selanjutnya data yang terkumpul di analisa dengan ANOVA. Karena tidak terdapat replikasi, populasi dari Imogiri tidak termasuk dalam analisis varian.

\section{HASIL DAN PEMBAHASAN}

A. Persen hidup tanaman

Kemampuan hidup Cendana yang bibitnya dikoleksi dari sebaran alam di Nusa Tenggara Timur, di lokasi baru Watusipat Gunung Kidul sangat penting. Persen hidup tanaman telah dijadikan salah satu parameter untuk mengukur daya adaptasi tersebut. Menurut Campbell dkk. (2000) persen hidup adalah persen peluang daya tahan hidup 
populasi, dan jangka waktu populasi dapat hidup.

Hasil analisis data persen hidup tanaman Cendana umur 11 tahun (Tabel 1) menunjukan bahwa variasi persen hidup tanaman diantara provenans cendana dalam plot konservasi tersebut tidak signifikan, berbeda saat berumur 9 tahun, dilaporkan Hadiyan dan Fiani (2014) bahwa persen hidup tanaman Cendana pada umur tersebut signifikan.
Rata-rata persen hidup tanaman (lihat gambar 2), menunjukkan secara berurutan provenans Rote memiliki persen hidup terbaik, kemudian Belu, Sumba dan dari TTU memiliki persen hidup terendah. Menurut Kramer dan Kozlowski (1960) penyebab rendahnya kemampuan hidup tanaman bisa disebabkan oleh faktor keturunan, genetik maupun lingkungan, Ditambahkan Surata (2006) faktor genetik seperti inbreeding juga dapat menjadi penyebab tanaman menjadi kurang.

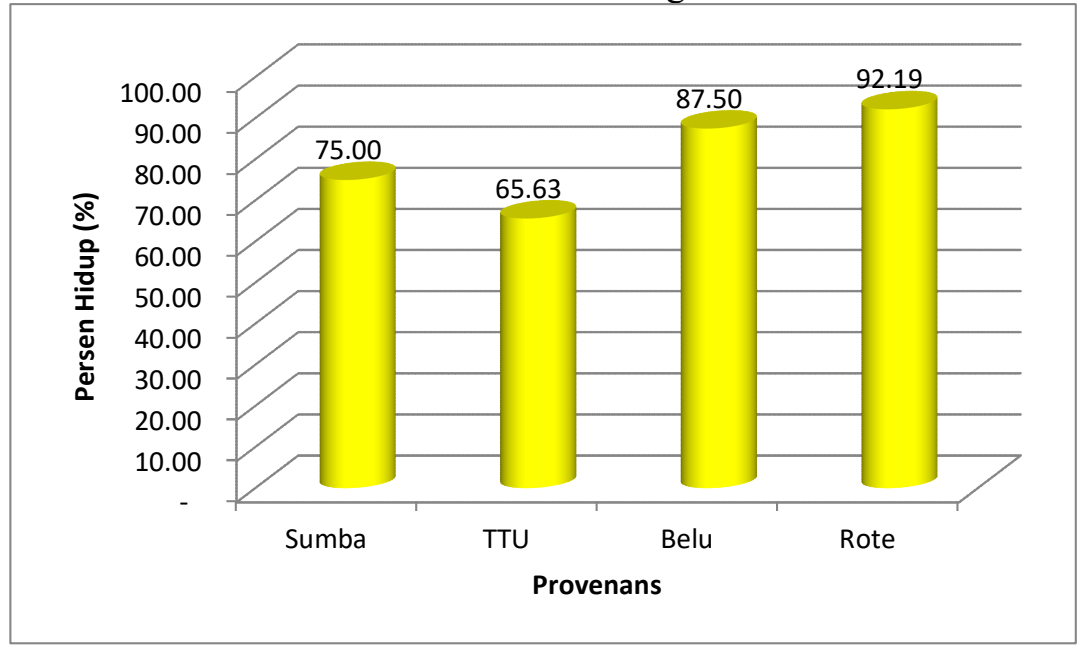

Gambar 2. Persen hidup tanaman Cendana umur 11 tahun di Watusipat Gunung Kidul.

Persen hidup tanaman Cendana di luar habitat alamnya tersebut termasuk baik, bahkan jika mengacu pada kriteria menurut Nirawati dkk. (2013) persen hidup tanaman dari 4 provenans yang mencapai $>65 \%$ tersebut dapat diklasifikasikan ke dalam "kelas berhasil". Di sisi lain, Pada habitat alaminya di NTT, persen hidup tanaman Cendana pada umur 8 tahun di provinsi NTT mencapai 49,54\% (Surata, 2010).

\section{B. Pertumbuhan Tanaman}

Dua variable yang menjadi fokus pengamatan dalam pertumbuhan Cendana di Watusipat tersebut adalah tinggi total tanaman dan diameter batang. Hasil analisis varian menunjukkan bahwa variasi tinggi tanaman antar provenans Cendana yang diuji berbeda nyata (Tabel 1) dengan kisaran rerata tinggi $4,2 \mathrm{~m}-6,5 \mathrm{~m}$.
Sedangkan hasil analisis varian diameter batang menunjukkan bahwa variasi antar provenans Cendana yang diuji berbeda nyata (Tabel 3) dengan kisaran rerata tinggi per provenans dengan kisaran diameter batang antara $3,5 \mathrm{~cm}-5,5 \mathrm{~cm}$.

Rerata pertumbuhan baik tinggi maupun diameter batang Cendana tersebut mengindikasikan adanya peningkatan jika dibandingkan dengan yang dilaporkan Hadiyan dan Fiani (2014) pada umur 9 tahun dimana rerata tinggi $4,1 \mathrm{~m}-5,8 \mathrm{~m}$ dan kisaran diameter batang $3,3 \mathrm{~cm}-4,8 \mathrm{~cm}$. Kondisi ini sesuai dengan yang digambarkan Troup (1921) dalam Surata dan Idris (2001), cendana mampu tumbuh pada kondisi iklim yang kering (tipe iklim D-E, menurut klasifikasi Schmidt dan Ferguson). 
Tabel 1. Analisis Varians Tinggi Tanaman Cendana umur 11 tahun di Watusipat Gunung Kidul.

\begin{tabular}{|l|r|r|r|r|l|}
\hline \multicolumn{1}{|c|}{$\begin{array}{c}\text { Sumber } \\
\text { Varian }\end{array}$} & $\mathrm{db}$ & \multicolumn{1}{c|}{ JK } & RK & F hitung & $\operatorname{Pr}>$ F \\
\hline & & & & & \\
\hline Blok & 3 & 1.64224998 & 0.54741666 & 0.63 & 0.6157 \\
\hline Provenans & 3 & 13.65302307 & 4.55100769 & 5.24 & $0.0272^{* *}$ \\
\hline Galat & 8 & 6.94683598 & 0.86835450 & & \\
\hline Total & 14 & 22.21561176 & & & \\
\hline
\end{tabular}

Ket: ** significant pada taraf uji $5 \%$

Tabel 2. Uji DMRT Tinggi Tanaman Cendana umur 11 tahun di Watusipat Gunung Kidul.

\begin{tabular}{|l|c|c|c|}
\hline $\begin{array}{c}\text { Pengelompokan } \\
\text { Duncan }\end{array}$ & Rerata & N & Provenans \\
\hline A & 6.55 & 4 & 4 \\
\hline B A & 5.04 & 3 & 3 \\
\hline B & 4.36 & 4 & 1 \\
\hline B & 4.22 & 4 & 2 \\
\hline
\end{tabular}

Keterangan: 1. Sumba; 2. TTU; 3. Belu; 4. Rote

Tabel 3. Analisis Diameter Tinggi Tanaman Cendana umur 11 tahun di Watusipat Gunung Kidul.

\begin{tabular}{|l|r|r|r|r|l|}
\hline $\begin{array}{c}\text { Sumber } \\
\text { Varian }\end{array}$ & $\mathrm{db}$ & \multicolumn{1}{c|}{ JK } & RK & F hitung & $\operatorname{Pr}>\mathrm{F}$ \\
\hline & & & & & \\
\hline Blok & 3 & 2.19572179 & 0.73190726 & 1.92 & 0.2044 \\
\hline Provenans & 3 & 9.80670365 & 3.26890122 & 8.59 & $0.0070^{* *}$ \\
\hline Galat & 8 & 3.04452596 & 0.38056575 & & \\
\hline Total & 14 & 15.11886196 & & & \\
\hline
\end{tabular}

Ket: ${ }^{* *}$ significant pada taraf uji $1 \%$

Tabel 4. Uji DMRT Diameter Tanaman Cendana umur 11 tahun di Watusipat Gunung Kidul.

\begin{tabular}{|l|c|c|c|}
\hline $\begin{array}{c}\text { Pengelompokan } \\
\text { Duncan }\end{array}$ & Rerata & $\mathrm{N}$ & Provenans \\
\hline A & 5.52 & 4 & 4 \\
\hline B A & 3.96 & 3 & 3 \\
\hline B & 3.82 & 4 & 1 \\
\hline B & 3.46 & 4 & 2 \\
\hline
\end{tabular}

Keterangan: 1. Sumba; 2. TTU; 3. Belu; 4. Rote

Adanya perbedaan yang sangat nyata tersebut baik untuk sifat tinggi tanaman maupun diameter batang menunjukkan adanya keragaman genetik yang tinggi. Hal tersebut dimungkinkan karena dipengaruhi dari asal provenans cendana tersebut (Haryjanto dan Pamungkas, 2005). Munurut Zobel, dan Talbert (1984) variasi tersebut dapat juga disebabkan oleh beberapa faktor, seperti perbedaan geografis.

\section{KESIMPULAN}

Studi adaptasi dan pertumbuhan tanaman Cendana umur 11 tahun di Watusipat Gunung Kidul tersebut dapat disimpulkan bahwa Cendana Provenans Rote memiliki daya adaptasi dan pertumbuhan terbaik, 
sedangkan sebaliknya Provenans TTU yang terendah. Rata-rata pertumbuhan tinggi dan diameter batang Cendana mengalami peningkatan cukup baik.

\section{DAFTAR PUSTAKA}

BBPBPTH, 2013. Sekilas Tentang Kawasan Hutan Dengan Tujuan Khusus Gunung Kidul Blok Watusipat.

BPS Provinsi Nusa Tenggara Timur, 2013. Luas Lahan Kritis di Dalam dan di Luar Kawasan Hutan Menurut Kabupaten/Kota, 2013. http://ntt.bps.go.id/linkTabelStatis/vie w/id/296. Diunduh pada 8 September 2017.

Campbell, N. A., Reece, J. B., dan Mitchell, L. G. 2000. Biologi edisi ke-5. Erlangga, Jakarta.

Darmokusumo, S., Nugroho, A.A., Botu, E.U., Jehamat, A., dan Benggu, M. Upaya Memperluas Kawasan Ekonomi Cendana di Nusa Tenggara Timur. . Edisi Khusus Masalah Cendana NTT. Berita Biologi, Volume 5, Nomor 5, Agustus 2001. P 509-513.

Hadiyan, Y. dan Fiani, A. 2016. Adaptability and Growth Performance of Sandalwood (Santalum album) Exsitu Conservation in Gunungkidul District, Indonesian. Naskah Penelitian Belum Dipublikasi. Yogyakarta

Haryjanto, L. dan Pamungkas, T. 2005. Variasi Pertumbuhan Cendana dari Berbagai Provenans pada Umur Delapan Bulan. Jurnal Penelitian Hutan Tanaman 2 (2): $88-94$

Hasan, M., H., dan Mongko, M., F., 2016. Adaptasi dan Mitigasi Fenomena El Nino di Provinsi Nusa Tenggara Timur. Prosiding Seminar Nasional
Geografi UMS 2016. https://publikasiilmiah.ums.ac.id/bitstr eam/handle/11617/8572/31 Muhamm ad\%20Husain $\% 20$ Hasan.pdf?sequenc $\underline{\mathrm{e}=1}$ diunduh pada 8 September 2017.

Kaho, MR. 2016. Inisiasi, praktik dan Pembelajaran Perubahan Iklim di NTT. Makalah Workshop REDD+ Indonesia Pasca Kesepakatan Paris. Kupang 28 November 2016.

Kramer, P. J. dan Kozlowski, T. T. 1960. Physiology of Trees. Mc Graw-Hill Book Co, New York.

Pemprov NTT, 2016. http://nttprov.go.id/ntt2016/index.php/ profildaerah1/kondisi-geografis.

Diunduh pada 8 September 2017.

Surata, I.K., dan Idris, M.M. 2001. Status Penelitian Cendana di Provinsi Nusa Tenggara Timur. Edisi Khusus Masalah Cendana NTT. Berita Biologi, Volume 5, Nomor 5, Agustus 2001. P 521-537

Surata, I.K. 2010. Pemanfaatan tegakan Acacia auriculiformis sebagai pohon penaung dan inang tanaman cendana (Santalum Album Linn). Jurnal Penelitian Hutan Tanaman Vol.7 No.5, Desember 2010, 241 - 251).

Surata, I. K. 2006. Teknik Budidaya Cendana. Dalam: Seminar Nasional Tentang Status Silvikultur di Indonesia Saat ini. Yogyakarta. Hal. 1-27.

The IUCN Red List of Threatened Species. Version 2017-1. $<$ www.iucnredlist.org $>$. Downloaded on 06 September 2017.

Zobel, B. J. dan Talbert, J. 1984. Applied Forest Tree Improvement. John Willey and Sons, New York. 